Matheus Borsato, Vinicius Machado de Oliveira, Da Produção Especializada à Inventividade Amadora... Marcos Roberto Brasil, Verônica Volski e

Juliano de Souza

\title{
DA PRODUÇÃO ESPECIALIZADA À INVENTIVIDADE AMADORA NO LEAGUE OF LEGENDS
}

Recebido em: 26/11/2018

Aceito em: 12/09/2019

Matheus Borsato

Vinicius Machado de Oliveira

Marcos Roberto Brasil

Verônica Volski

Juliano de Souza

Universidade Estadual de Maringá (UEM)

Maringá - PR - Brasil

RESUMO: Com a chegada da segunda modernidade ou pós-modernidade temos presenciado inúmeras mudanças na sociedade. Dentre as principais, tem se destacado o desenvolvimento tecnológico. A influência é tão grande que a tecnologia já se encontra presente em vários segmentos de nossas vidas, principalmente em atividades de lazer e entretenimento. Nessa esteira, podemos exemplificar a expansão dos jogos eletrônicos, em especial, o caso paradigmático do League of Legends que é um dos títulos mais jogados ao redor do mundo. Em linhas gerais, esse jogo, em particular, abriu a discussão para o processo de esportivização dos jogos eletrônicos, gerando questionamentos tanto no âmbito do senso comum como também no campo acadêmicocientifico. Sabendo dessa inquietação, este estudo teve por objetivo compreender o campo do League of Legends, percorrendo pela estrutura do subcampo dos profissionais até o espaço da reprodução inventiva.

PALAVRAS-CHAVE: Jogos de Vídeo. Atividades de Lazer. Sociologia do Esporte.

\section{FROM SPECIALIZED PRODUCTION TO AMATEUR INVENTIVITY IN LEAGUE OF LEGENDS}

ABSTRACT: With the arrival of the second modernity or postmodernity we have seen changes in society. Among the main, the technological development that has changed the way human beings live in the social space. The influence is so great that technology is already present in various segments of our lives, especially in leisure and entertainment. In this context, we can exemplify the expansion of electronic games, in particular, the paradigmatic case of the League of Legends which is one of the most played games around the world. In general terms, this game, in particular, opened the discussion to the process of sportivization of electronic games, generating tactful questions within the scope of common sense as well as in the academic-scientific field. Knowing this uneasiness, this study aimed to understand the cyber (sportive) field of the League of Legends, going through the structure of the subfield of professionals to the space of inventive reproduction. 
Matheus Borsato, Vinicius Machado de Oliveira, Da Produção Especializada à Inventividade Amadora... Marcos Roberto Brasil, Verônica Volski e

Juliano de Souza

KEYWORDS: Video Games. Leisure Activities. Sociology of Sport.

\section{Introdução}

Dentre as diversas mudanças figuracionais ao longo do processo civilizador (ELIAS, 2008, 2011), o desenvolvimento tecnológico é, possivelmente, uma das etapas mais notáveis do desenvolvimento das sociedades. Em outros termos, nas últimas décadas, vivenciamos e temos presenciado dia a dia um ritmo de evolução tecnológica frenético, que tem alterado a nossa forma de se relacionar e interagir com as pessoas no tecido social. A influência do mundo digital em nossas vidas é tão impactante, que os diversos dispositivos eletrônicos utilizados no cotidiano, são quase que uma extensão de nossa hexis corporal, ou seja, uma cultura tornada a corpo que se objetiva nos seres humanos face às suas condições sociais de produção (BOURDIEU, 2012).

Em paralelo com esse fenômeno, a relação dos indivíduos com a tecnologia tem sido cada vez mais alvo de inquietação e investigação na literatura, instigando pesquisadores do mundo todo a desvendar os diversos fatores e aspectos que circundam este evento da segunda modernidade ou da sociedade pós-tradicional, se pensarmos com Beck (2010) e Giddens (1991), respectivamente. Diante desse quadro, alguns teóricos já se arriscam em até estabelecer conceitos e rótulos para a relação entre homem e tecnologia, em especial, acerca dos jovens que, em grande medida, já nascem imbricados nessa nova dinâmica social.

Dessa forma, entre os conceitos que ganharam repercussão nas últimas décadas, destaca-se a ideia de "nativos digitais", "geração net", "geração delivery", "geração digital", "geração Playstation", dentre outros (TAPSCOTT, 1997; PRENSKY, 2001; ALMEIDA, 2008; PALFREY; GASSER, 2011). Todavia, independente da 
Matheus Borsato, Vinicius Machado de Oliveira, Da Produção Especializada à Inventividade Amadora... Marcos Roberto Brasil, Verônica Volski e

Juliano de Souza

conceituação atribuída, todas indicam que a nova geração nasceu e eclodiu nesse contexto, em que a tecnologia é encarada com muita naturalidade. Ou seja, a manipulação e a utilização dos diversos dispositivos, entre os quais, computadores, celulares, videogames e entre outros, são controlados com muito conforto e destreza pelas crianças e jovens.

Não obstante, essa relação entre indivíduos e tecnologia não se resume apenas entre as gerações mais novas, pelo contrário, existe um forte movimento das linhagens mais velhas, as quais não estão alheias a conformação social vigente. Nesse particular, o que muda, é que as pessoas nascidas antes da imersão digital e do boom da internet, ainda estão se adaptando a nova tessitura da sociedade, realizando a conversão do habitus para conviver e interagir com aqueles que se encontram habituados com as inovações tecnológicas. De acordo com pesquisadores na literatura, os indivíduos mais velhos podem ser compreendidos como “imigrantes digitais" (PRENSKY, 2001; PALFREY; GASSER, 2011).

Mas, independente da genealogia, fato é, que as sociedades mais diferenciadas, foram arrebatadas pelas tecnologias, adentrando os diversos segmentos da vida (pós) moderna, desde as atividades relacionadas ao âmbito do trabalho até o contexto de lazer. Contudo, como vivemos um momento em que as pessoas estão continuamente mais reflexivas (BECK; GIDDENS; LASH, 1997), os indivíduos não se sentem mais confortáveis em ficarem somente numa posição de passividade face às tecnologias, ou seja, para além de consumir, é necessário também interagir e participar (JENKINS, 2008). É nesse contexto, que os jogos eletrônicos emergem como uma das formas mais expressivas de entretenimento da atualidade (FINCO; FRAGA, 2013). 
Matheus Borsato, Vinicius Machado de Oliveira, Da Produção Especializada à Inventividade Amadora... Marcos Roberto Brasil, Verônica Volski e

Juliano de Souza

Em consonância a esse cenário, não há dúvidas de que os jogos eletrônicos em suas diferentes plataformas estão mais populares e rentáveis do que nunca (KAHN, et al., 2015; LLORENS, 2017). Mais do que isso, com o advento da internet, os jogos eletrônicos ganharam outra dimensão, expandindo as redes relacionais entre jogadores do mundo todo (BERTRAN; CHAMARRO, 2016). Em linhas gerais, gostando ou não, os jogos digitais acabaram ganhando espaço em meio às práticas tradicionais, incorporando novas formas e alternativas de jogar e de se praticar esporte. É justamente nessa direção que essa modalidade transita do lazer para o esporte, passando por um importante processo de esportivização, que vai desde a regulamentação do jogo, até as dinâmicas de espetacularização e mercantilização da prática (ROCHA; RODRIGUEZ; VITÓRIA, 2016; LLORENS, 2017; LEITINHO; FARIAS, 2018).

E um dos casos mais paradigmáticos na indústria dos jogos eletrônicos, que tem consubstanciado a questão do e-Sports no globo, é o jogo online da produtora Riot Games - "League of Legends”. Em síntese, trata-se de um dos jogos multiplayers mais jogados ao redor do mundo, movimentando cifras na casa dos bilhões de dólares anuais, estimulado pela prática amadora e profissional (KAHN, et al., 2015; LI, 2016; LLORENS, 2017; GRAY et al., 2018). Portanto, não à atoa, vemos que esse game tem sido cada vez mais objeto de investigação em várias pesquisas sobre determinados contextos. Porém, no âmbito da Sociologia do Esporte, os estudos ainda em estão em desenvolvimento na literatura. Assim, resta uma ampla gama de possibilidades e inquietações a serem perscrutadas no campo acadêmico científico.

Em suma, o League of Legends é um fecundo espaço social de investigação das relações sociais, que pode revelar inúmeros fatores acerca do novo movimento reflexivo instaurado em nossas sociedades, tidas como (pós) modernas. Nesse particular, sabendo 
Matheus Borsato, Vinicius Machado de Oliveira, Da Produção Especializada à Inventividade Amadora... Marcos Roberto Brasil, Verônica Volski e

Juliano de Souza

das potencialidades do estudo sociológico do $e$-Sports, esta pesquisa tem como objetivo compreender os subcampos do profissionalismo e amadorismo do League of Legends, partindo da hipótese de que as relações socioesportivas nesse campo, se dão a partir do entendimento do espaço dos produtores, somado a reprodução inventiva inconsciente da prática tornada a corpo. Isto é, se pensarmos na ótica de Beck; Giddens e Lash (1997), a ideia é que os jogadores, independentemente da posição que ocupam no ambiente de jogo, estão mais reflexivos e partilham dos mesmos hábitos, ainda que pertençam a subcampos diferentes.

Dito isso e para cumprir com o desiderato propositado, seccionamos a nossa pesquisa em três frentes principais de investigação. Na primeira seção, procuramos apresentar o campo do e-Sports, em especial, o objeto investigado, o League of Legends. Introduzido o contexto desse jogo, na segunda seção do trabalho, investimos na investigação do subcampo profissional da prática. Por fim, na terceira e última parte do trabalho, buscamos compreender a lógica dos reprodutores no espaço social dos amadores.

\section{Encaminhamentos Teórico-Metodológicos}

Como encaminhamentos metodológicos para o cumprimento dos objetivos aqui postulados, conduzimos uma pesquisa de incursão exploratória e bibliográfica ao campo de investigação. Em linhas gerais, realizamos uma imersão ao universo do League of Legends, partindo do pressuposto bourdieusiano, que para melhor compreender as nuanças e peculiaridades do campo, é necessário possuir o habitus e pertencer a realidade investigada (BOURDIEU, CHAMBOREDON; PASSERON, 2002; 
Matheus Borsato, Vinicius Machado de Oliveira, Da Produção Especializada à Inventividade Amadora... Marcos Roberto Brasil, Verônica Volski e

Juliano de Souza

BOURDIEU, 1998; 2009). Nesse caminho, passamos na continuidade aos procedimentos teórico-metodológicos.

Como meios e fontes de investigação, coletamos e abstraímos as informações da pesquisa através de [1] artigos na literatura, [2] blogs e sites especializados nos e-Sports e no LoL, [3] fóruns e chats do jogo, e [4] streams dos campeonatos nacionais e internacionais realizados pela produtora do LoL. Todos esses elementos compuseram o quadro das ferramentas e fontes de levantamento dos dados da pesquisa. Para o tratamento analítico das informações, mobilizamos alguns dos conceitos operacionais da teoria bourdieusiana. Em paralelo as contribuições de Bourdieu, acessamos perifericamente o referencial teórico de Norbert Elias ao longo do estudo.

\section{Press Start - E-Sports: O Campo do League of Legends}

Como é de conhecimento, os últimos anos têm sido notoriamente marcados pelo desenvolvimento tecnológico. Os diversos tipos de tecnologia já estão em vários segmentos de nossas vidas, não só direcionados para o cotidiano e as rotinas de seriedade, como também imersos em nossas atividades de lazer e divertimento. Dessa forma, o entretenimento digital há algum tempo, já vem dividindo espaço com as atividades tradicionais, possibilitando novas e diferentes formas de se relacionar com o âmbito do lazer. No entanto, como sabemos, não se trata de uma forma passiva de entretenimento, pelo contrário, em concomitância com o avanço tecnológico, as pessoas têm sentido cada vez mais a necessidade de participação e interação com os conteúdos (JENKINS, 2008), exigindo que as novas tecnologias atendam a atual configuração social, tida como (pós) moderna. 
Matheus Borsato, Vinicius Machado de Oliveira, Da Produção Especializada à Inventividade Amadora... Marcos Roberto Brasil, Verônica Volski e

Juliano de Souza

É nesse cenário, sobretudo no presente século, que os jogos eletrônicos surgem como uma ferramenta substancialmente imersiva de entretenimento, estando presente em diversos dispositivos, desde compactos smartphones até aos consoles e computadores (BERTRAN; CHAMARRO, 2016). Em linhas gerais, esse tipo de divertimento alcançou proporções de grande magnitude no mundo todo, ultrapassando outras potenciais plataformas de divertimento, como por exemplo, a legitimada indústria das produções cinematográficas (ŠTAVLJANIN; CVIJOVIĆ; KOSTIĆSTANKOVIĆ, 2017).

Contudo, os jogos eletrônicos não ficaram somente presos a lógica de entretenimento. Com o passar dos últimos anos, essa prática corporal ganhou outras dimensões e significados na sociedade, sendo construída a partir da reflexividade da comunidade de players ao redor do globo. E quando sugerimos o globo, reconhecemos que a internet foi um dos fatores decisivos para a expansão dos jogos eletrônicos, pois, além de interligar os jogadores, permitiu criar novas possibilidades em relação à prática, tais como os jogos online em seus múltiplos estilos e gêneros. Em resumo, ao contrário do que se costuma pensar face ao senso comum, a internet potencializou as relações sociais entre os jogadores, haja vista que, com essa possibilidade, os indivíduos puderam expandir as redes de contato para além do círculo restrito de amizades.

E diante dessa dinamicidade relacional provida pela internet, é que nasceram os jogos multiplayer, isto é, jogos que podem ser vivenciados simultaneamente por milhares de pessoas em um mesmo ambiente (BERTRAN; CHAMARRO, 2016), um ambiente criado, que visa conferir emoções e sentimentos, tal qual os esportes e outras práticas de lazer propiciam. É justamente por esses indicativos, principalmente no que se refere ao contexto emocional, que os jogos digitais receberam características de 
Matheus Borsato, Vinicius Machado de Oliveira, Da Produção Especializada à Inventividade Amadora... Marcos Roberto Brasil, Verônica Volski e

Juliano de Souza

competitividade nos últimos anos. Se antes era possível apenas competir com o computador ou com um número muito limitado de pessoas, atualmente, os jogadores podem desafiar qualquer oponente do mundo, bastando apenas estar conectado aos servidores do jogo de interesse.

Esses jogos que são emulados em comunicação com a rede de computadores são denominados de Massively Multiplayer Online, os MMOs. Dentre os jogos dessa categoria, destacam-se os Multiplayer Online Battle Arena (MOBAs), gênero que abriga um dos games mais consumidos de todos os tempos, a saber, o League of Legends, ou mais popularmente conhecido como LoL (KAHN et al., 2015; KOKKINAKIS; et al., 2016; RIPAMONTI, et al., 2018; GRAY et al., 2018).

O LoL foi criado em 2009 pela produtora de jogos eletrônicos Riot Games, e é um dos jogos de computadores mais populares da atualidade. Estimativas dão conta que em 2014 a plataforma chegou a expressiva marca de 67 milhões de players por mês, com uma média de 27 milhões de conexões diárias aos servidores do game (KOKKINAKIS; et al., 2016; LLORENS, 2017; GRAY, et al., 2018). Mas esses números astronômicos não param por aí. Nos últimos anos, o LoL se tornou um dos esportes eletrônicos mais predominante do mundo dos games, atingindo uma receita anual, que ultrapassa a marca de 1 bilhão de dólares (LI, 2016) e também acumula mais de 1 bilhão de horas jogadas todos os anos, o que representa mais da metade do segundo colocado, que é o World of Warcraft, com aproximadamente 600 milhões de horas (BELL, 2017). Vale ressaltar que esses dados continuam sendo modificados a cada ano. Em termos de mecânica do jogo, o LoL nada mais é que um MOBA combinado com elementos do gênero de jogo RTS (Real-Time Strategy) aliado as características de um RPG (Role-Playing Game) (WATSON, 2015; SAPIENZA, et al., 2018). Como 
Matheus Borsato, Vinicius Machado de Oliveira, Da Produção Especializada à Inventividade Amadora... Marcos Roberto Brasil, Verônica Volski e

Juliano de Souza

qualquer outro MOBA, o LoL é um jogo de estratégia e cooperação, competido entre duas equipes, em que os jogadores duelam entre si, cada um controlando um personagem diferente (MORA-CANTALLOPS; SICILIA, 2018). Em síntese, trata-se de um jogo distribuído em duas equipes com cinco jogadores cada, sendo semelhante ao que podemos chamar de uma espécie de "caça-bandeira virtual" (BELL, 2017). Todavia, ao invés de capturar bandeiras no campo de jogo, o objetivo central do game é destruir todas as torres da equipe adversária, até chegar a destruição da base inimiga, chamada de "nexus" (DONALDSON, 2015; GRAY, et al., 2018; MORACANTALLOPS; SICILIA, 2018). Assim, quando uma equipe neutraliza todas os alvos do time oponente, a mesma chega a vitória.

Além do objetivo central do jogo, há também metas individuais dentro da partida, como por exemplo, se manter o maior tempo no campo de jogo, alcançando o maior número de kills possível durante o confronto (SAPIENZA et al., 2018). Nesse sentido, quando os jogadores apresentam uma boa performance, vantagens são atribuídas ao jogador e a equipe. Entre as recompensas por bom desempenho durante a partida, está o ganho de ouro, que é a moeda do jogo, a qual pode ser utilizada para compras de itens que potencializam as habilidades e o rendimento do personagem nas batalhas (SAPIENZA; BESSI; FERRARA, 2018).

Em relação aos avatares do jogo, os jogadores assumem personagens denominados de "campões" durante as partidas. Desse modo, cada membro da equipe escolhe um super-herói jogável, sendo obviamente diferente entre os membros do grupo. Em resumo, são mais de 100 personagens, cada um com seu próprio conjunto de técnicas, poderes, ataques, defesas, habilidades e funções específicas no jogo (DONALDSON, 2015; BELL, 2017). Assim como qualquer outro esporte coletivo, o 
Matheus Borsato, Vinicius Machado de Oliveira, Da Produção Especializada à Inventividade Amadora... Marcos Roberto Brasil, Verônica Volski e

Juliano de Souza

LoL também apresenta distribuição dos jogadores em posições, ou seja, cada personagem cobre um setor do campo e uma determinada responsabilidade durante a partida (MORA-CANTALLOPS; SICILIA, 2018).

Atualmente o LoL possui três mapas jogáveis, sendo Summoner's Rift, Twisted Treeline e Howling Abyss. Cada mapa possui as suas especificidades, tendo que os jogadores estarem atentos a essas nuanças, bem como ao estilo e a estratégia de jogo da equipe adversária. Conforme os jogadores vão avançando e adquirindo experiência no game, os mesmos passam por um sistema de ranqueamento, subdividido por níveis de excelência. No total são sete classificações crescentes: Bronze, Silver, Gold, Platinum, Diamond, Master and Challenger (BELL, 2017). De um modo geral, as divisões mais populosas são a Silver, seguidos da classificação Bronze e Gold. No total, se somada essas divisões, as mesmas representam aproximadamente $90 \%$ da base de jogadores do LoL (MORA-CANTALLOPS; SICILIA, 2018). Apenas uma pequena fração consegue atingir os níveis Master and Challenger, que nada mais é, que o subcampo dos profissionais.

É justamente essa estrutura organizacional que torna o LoL tão atraente, pois além do entretenimento inserindo ao conteúdo do game, o sistema de classificação estimula a competição. É por isso, que essa atividade profissional vem crescendo em relação a esse jogo. E o Brasil não está alheio esse fenômeno, representando a sexta maior base de jogadores de League of Legends do mundo, o país já conta com servidor próprio desde o ano de 2012 (PETRÓ, 2013). Em síntese, o mercado brasileiro chamou tanta a atenção da Riot Games, que a empresa investiu cerca de 5 milhões de dólares nos últimos anos na região, procurando adaptar da melhor forma a plataforma no país (HONORATO, 2012). 
Matheus Borsato, Vinicius Machado de Oliveira, Da Produção Especializada à Inventividade Amadora... Marcos Roberto Brasil, Verônica Volski e

Juliano de Souza

Em linhas gerais, não é possível desprezar a ideia, de que o LoL é uma prática corporal de dimensões intercontinentais, que sustenta um campo, cujos adeptos constituem e partilham um mesmo habitus, mesmo estando escalonados por posições e capitais diferentes. De fato, se pensarmos com Bourdieu, o habitus fundamenta o estilo de vida dos jogadores, tanto no âmbito do profissionalismo como também no amadorismo. É nesse sentido, que procuramos investigar esse universo, partindo primeiro da compreensão e da defesa do subcampo profissional da prática, até chegarmos ao espaço dos amadores ou reprodutores.

\section{O Subcampo dos Produtores: O Profissionalismo no League of Legends}

Como pudemos constatar através de buscas na web e da própria literatura, o LoL é um dos jogos multiplayer mais jogados ao redor do mundo. Condição que ao longo do tempo mediante a tendências paralelas no cenário mundial, permitiu atribuir características concretas de esportivização a esta modalidade do âmbito virtual. Assim como outras práticas, a exemplo do xadrez (SOUZA; MARCHI JÚNIOR, 2013), o LoL também se movimentou do jogo para o esporte, a partir do momento que uma série de fatores sinalizou que essa prática não se tratava mais apenas de uma atividade de divertimento qualquer. Longe disso, toda atmosfera envolvida em torno do jogo, evidencia aspectos do esporte.

Dessa forma, as próprias mudanças na sociedade foram determinantes para que o LoL passasse a ser encarado como uma prática esportiva, ainda que no contexto ciberespaço. Ou seja, aliado a questão do jogo e do divertimento que é um produto do processo civilizador (ELIAS; DUNNING, 1992; ELIAS, 2011), foi necessário também o desenvolvimento tecnológico, sobretudo dos dispositivos e da internet, em paralelo 
Matheus Borsato, Vinicius Machado de Oliveira, Da Produção Especializada à Inventividade Amadora... Marcos Roberto Brasil, Verônica Volski e

Juliano de Souza

com as novas dinâmicas do mercado do esporte (LI, 2016; LLORENS, 2017; GRAY et al., 2018). Em síntese, o subcampo profissional da prática dos jogos eletrônicos não surgiu do nada, foi preciso todo um processo de desenvolvimento, atrelado a uma série de tendências paralelas da sociedade.

Portanto, as diversas práticas corporais acompanham os desdobramentos que ocorrem no tecido social, comportamento que Elias e Dunning (1992) verificaram ao estudar a sociedade inglesa, onde atribuíram à gênese do esporte moderno à Inglaterra. De um modo geral, esses teóricos da Sociologia do Esporte, perceberam que a estrutura social que os ingleses partilhavam entre os séculos XVIII e XIX, foi fundante para que as práticas não regulamentadas de lazer e divertimento, ganhassem cada vez mais características de esporte. Se transportada essa mesma interpretação social para o LoL, a transformação do jogo para o esporte, só ocorreu por conta da conformação da sociedade atual, que já possui os elementos para que isso acontecesse. Mas, para além do advento da internet, que foi um dos aspectos estruturantes para a expansão do LoL, quais seriam os aspectos que nos permitem caracterizar essa nova prática corporal como um esporte (pós) moderno?

Em primeiro lugar, é importante considerar que o jogo possui oposição entre equipes, o que acaba contribuindo para a competitividade. Nessa tessitura, está envolvida toda uma atmosfera de rivalidade, bem como a capacidade estratégica de cada time. Em função disso, o LoL apresenta altas doses de excitação-tensão, um dos elementos essenciais na prática esportiva. De acordo com Norbert Elias (1992, 2011), o esporte foi um dos mecanismos mais importantes para o avanço do processo civilizador nas sociedades modernas, pois pôde transferir as pulsões humanas para contextos miméticos. Isto é, se com o desenvolvimento da sociedade não era mais permitido 
Matheus Borsato, Vinicius Machado de Oliveira, Da Produção Especializada à Inventividade Amadora... Marcos Roberto Brasil, Verônica Volski e

Juliano de Souza

externalizar as pulsões de qualquer jeito no âmbito das rotinas de seriedade, o esporte permitiu gerar doses de catarse, sem ferir com os códigos de conduta inseridos no tecido social (ELIAS; DUNNING, 1992).

Nesse contexto, as pulsões humanas não desapareceram com o avanço da civilidade, mas ao contrário, foram apenas redirecionadas para lugares que permitissem o controle descontrolado das emoções (ELIAS; DUNNING, 1992). E o LoL, certamente, tem sido um desses espaços, pelo menos para milhares de pessoas no mundo todo, que buscam no jogo, divertimento, excitação, tensão, catarse e uma série de outros elementos atrelados ao âmbito esportivo. Dessa forma, em se tratando de campo, não há como negligenciar o fato de que o LoL, possui inúmeros aspectos que estão associados ao campo do esporte.

Como está circunscrito na literatura bourdieusiana, o campo pode ser compreendido socialmente como um espaço de lutas, um campo de jogo, em que os agentes competem entre si nas mais diversas posições (BOURDIEU, 1983). Nesse campo de lutas, os agentes mobilizam inúmeras estratégias para conseguir os capitais específicos do espaço, estabelecendo gradativamente uma lógica de dominados e dominantes (BOURDIEU, 1996a). No entanto, ainda que se trate de um campo de tensionamentos entre os indivíduos, os agentes mantêm o interesse de preservação do campo, em uma espécie de "cumplicidade objetiva", mesmo estando envoltos por uma relação de disputa e luta (LAHIRE, 2017). Ou seja, embora exista o contexto de oposição entre os agentes, os mesmos partilham relações de interdependência (ELIAS; DUNNING, 1992).

Portanto, visto pelo prisma sociológico, o LoL possui inúmeras características sociais, que nos permite enquadrá-lo dentro do campo esportivo, logicamente, 
Matheus Borsato, Vinicius Machado de Oliveira, Da Produção Especializada à Inventividade Amadora... Marcos Roberto Brasil, Verônica Volski e

Juliano de Souza

respeitando as suas especificidades, tendo em vista que cada campo possui a sua relativa autonomia e é operacionalizado por leis próprias, como nos alerta Bourdieu (2014). Nessa senda, face a leitura sociológica, sobretudo em relação ao referencial teórico bourdieusiano e eliasiano, há elementos suficientes para nos fazer refletir sobre o LoL quanto esporte. Não obstante, existem outros aspectos para além da dimensão sociológica, e que se diga de passagem, já dariam conta de firmar o LoL como prática esportiva da sociedade (pós) moderna. Entre um dos aspectos mais fortes, diz respeito ao processo de profissionalismo da prática.

Como é de conhecimento, o LoL possui inúmeras competições ao redor do mundo e que movimenta o cenário dos e-Sports. Se feito um mapeamento dos campeonatos, já é possível localizar uma série de eventos e ligas nesse sentido. Nessa esteira, podemos citar as competições asiáticas, tais como o "League of Legends Champions Korea" (LCK) realizado na Coréia do Sul, o "League of Legends Pro league" (LPL), na China, e o "League of Legends Master Series" (LMS), em Taiwan, Hong Kong e Macau (LLORENS, 2017; RIBEIRO, 2018). É importante sinalizar a proeminência dos asiáticos nesse contexto, em especial, a Coréia do Sul, que possui as equipes com mais títulos mundiais da modalidade.

Além da influência dos campeonatos asiáticos e do campeonato mundial, há também as competições em outras regiões do mundo, organizados pela própria produtora do jogo, a Riot Games. Destacam-se, portanto, o League of Legends Championship Series (LCS) realizado na América do Norte e Europa (LLORENS, 2017; RIBEIRO, 2018), e no Brasil, o Campeonato Brasileiro de League of Lengends o “CBLoL". Obviamente, existem outras competições, porém, essas já denotam o processo de profissionalismo da prática. 
Matheus Borsato, Vinicius Machado de Oliveira, Da Produção Especializada à Inventividade Amadora... Marcos Roberto Brasil, Verônica Volski e

Juliano de Souza

Todavia, associado as competições, vem outros elementos que reforçam a ideia que o LoL já possui características de atividade profissional, como por exemplo, os grandes patrocinadores que investem nas equipes. Nesse sentido, é oportuno citar a Samsung e a Sk Telecom, que patrocinam as equipes coreanas (GOETOMO, 2016). No Brasil, o LoL ganhou tanta repercussão, que grandes clubes de futebol decidiram entrar nesse espaço, financiando equipes próprias ou estabelecendo parcerias, como foi ou é o caso do Corinthians, Flamengo, Santos, entre outros (ROX, 2017). Além disso, a mesma tendência foi observada em grandes equipes de basquetebol, a exemplo da liga americana, a NBA (SPORTV, 2017). Esse comportamento, sugere que os gigantes do esporte tradicional têm percebido potenciais nessa prática e que ao constituir parcerias com esse novo segmento, agrega algumas vantagens.

E entre as prerrogativas, além, é claro, do capital econômico, está a visibilidade, visto que no decorrer do tempo a prática profissional do LoL passou por um grande processo de espetacularização da modalidade, atraindo milhares de pessoas para os eventos da marca. Só nas finais do mundial de 2016, transmitidas em 18 idiomas, o evento teve uma audiência de mais de 40 milhões de telespectadores (FU et al., 2017). Nas finais do ano seguinte, foi registrado o maior pico de visualizações em números oficiais, chegando aos 80 milhões de pessoas conectadas de alguma forma com a transmissão do evento (RODRIGUES, 2017).

Não alheia a essa audiência, canais esportivos têm estabelecido parcerias com a produtora do jogo, transmitindo em suas emissoras de TV, partidas em tempo real, como é o caso da ESPN no contexto internacional (LLORENS, 2017), e a própria Sportv, no Brasil. Em suma, recentemente, tais canais têm destinado espaço em suas grades de programação para uma série de modalidades do eSport, que vai além do 
Matheus Borsato, Vinicius Machado de Oliveira, Da Produção Especializada à Inventividade Amadora... Marcos Roberto Brasil, Verônica Volski e

Juliano de Souza

próprio pioneirismo do LoL. Certamente, essas instituições perceberam que essas práticas têm tido uma grande aceitação e tem movimentado um grande mercado para esse tipo de entretenimento. Mais do que isso, ao se apoiar no sucesso do LoL, esses segmentos de fora do campo, visam maximizar as suas estratégias para a obtenção de capitais e posição de dominância em seus respectivos campos, e assim, ao obter mais capitais, constroem um capital simbólico, conforme nos sugere Bourdieu (1996a; 2007).

Mas, as possíveis comparações entre LoL e práticas profissionais do campo esportivo não param por aí. Outro forte aspecto em torno do jogo, são as premiações dos campeonatos, que podem alcançar quantias elevadas, a exemplo do campeonato mundial, que paga todos os anos premiações na casa dos milhões de dólares. Embora no Brasil esse valor seja mais modesto, o CBLoL já chegou a pagar 200 mil reais em premiações, além de outros benefícios contratuais para as equipes vencedoras (FERRANTINI, 2018). Vale ainda ressaltar, que os jogadores profissionais de alto nível, participam de várias competições ao longo do ano, podendo acumular grandes quantias apenas com as premiações das ligas, como é o caso do sul coreano Lee Faker, um dos (ciber) atletas mais bem pagos da modalidade.

Contudo, o capital econômico acumulado pode ser maior na medida em que os jogadores assinam contratos com diversos patrocinadores, assim como ocorre nos esportes tradicionais. Mas, o sucesso no LoL não vem por acaso. Os jogadores precisam se dedicar a rotinas exaustivas de treinamento, para se manter em alto rendimento e performance. Em resumo, essa condição é sinônimo de dedicação exclusiva a atividade profissional, tal por isso, alguns (ciber) atletas tendem a ser bem remunerados.

Além disso, diante destes vários aspectos atrelados ao profissionalismo dos $e$ Sports, recentemente acendeu a discussão sobre o vínculo empregatício e o direito a 
Matheus Borsato, Vinicius Machado de Oliveira, Da Produção Especializada à Inventividade Amadora... Marcos Roberto Brasil, Verônica Volski e

Juliano de Souza

carteira de trabalho assinada aos jogadores. Nessa senda, de acordo com alguns juristas, a própria Lei Pelé possui brechas que permitem enquadrar os (ciber) atletas as mesmas prerrogativas dos esportes tradicionais (ARAUJO, 2018). Mais do que isso, a comunidade jurídica vai além, e defende que mesmo se não houvesse sustentação na referida lei, os jogadores profissionais de LoL ou de qualquer outro e-Sports, já estariam amparados pela justiça (ARAUJO, 2018). Ou seja, se as equipes ou patrocinadores não estiverem de acordo com as leis trabalhistas, as mesmas estão sujeitas a responder juridicamente. Portanto, no alto rendimento, está bem demarcado o processo de profissionalismo.

Por fim, vale dizer que o efeito da atividade profissional acerca do LoL tem sido tão intenso, que o habitus incutido no espaço dos especialistas, tem influenciado o reduto dos amadores. Em outros termos, os profissionais, como dominantes e detentores dos capitais da prática, ditam a dinâmica do campo, influindo diretamente no estilo e no habitus dos agentes tidos como amadores neste universo. São essas pequenas peculiaridades que buscamos rastrear em nossa última seção do estudo, compreendendo o subcampo dos reprodutores.

\section{O Subcampo dos Reprodutores: O Amadorismo no League of Legends}

No início, quando a produtora Riot Games criou o LoL, era evidente que essa softhouse não imaginaria que esse jogo seria um dos mais bem-sucedidos entre os players do mundo todo. Para além disso, é provável que a produtora não tivesse ideia que o jogo iria se tornar um esporte altamente rentável para os diversos segmentos do mercado. Ou seja, no princípio e até hoje, acreditamos que o intuito principal do LoL é fornecer entretenimento, tendo em vista que a maioria dos jogadores são 
Matheus Borsato, Vinicius Machado de Oliveira, Da Produção Especializada à Inventividade Amadora... Marcos Roberto Brasil, Verônica Volski e

Juliano de Souza

casuais/amadores que compartilham do habitus do jogar, não sendo muito diferente do estilo que se estabelece no subcampo dos profissionais. É em relação a essas nuanças, que direcionamos nossos esforços agora.

Como já discorrido na parte introdutória deste manuscrito, os jogos eletrônicos são frutos, em alguma medida, de uma sociedade pós-tradicional, se refletirmos com Giddens (1991). Em outras palavras, as práticas mais tradicionais, desde as brincadeiras de rua até os esportes mais comuns na sociedade (futebol, basquete, vôlei etc.), começam a dividir espaço com as novas práticas da época, tida como (pós) moderna. É nesse intermeio, que os jogos eletrônicos ganham mais adeptos diariamente, constituindo novas figurações no âmbito do lazer e do esporte.

De acordo com alguns levantamentos da indústria dos jogos eletrônicos, estimase que no mundo todo há mais de 2,3 bilhões de jogadores ativos, movimentando uma receita anual que deve chegar a quase 140 bilhões, só no ano de 2018 (NEWZOO, 2018a). O Brasil, é o terceiro país com a maior base de jogadores, contabilizando a marca de 75 milhões de pessoas ativas em relação a esse entretenimento, com um mercado que atualmente ocupa a $13^{\circ}$ posição e movimenta em torno de 1,5 bilhões de dólares anuais (NEWZOO, 2018b).

Como já mencionado, o LoL está entre os jogos mais consumidos do mundo e contribui para o crescimento dos dados supracitados. Embora esse jogo possua sua via profissional, está claro que a maioria dos jogadores são casuais e amadores, que jogam simplesmente pelo entretenimento proporcionado pelo game. Contudo, isso não quer dizer que os amadores se encontram desconectados da esfera profissional. Longe disso, partilham de muitos aspectos desse espaço e inclusive, absorvem as influências dos agentes tidos como dominantes da prática. 
Matheus Borsato, Vinicius Machado de Oliveira, Da Produção Especializada à Inventividade Amadora... Marcos Roberto Brasil, Verônica Volski e

Juliano de Souza

Obviamente, os amadores possuem menos poder quando comparado com os profissionais, haja vista que esses últimos, dividem posições que são constituídas por mais capitais. Dito de outra forma, quanto mais capitais um grupo possui, maior a possibilidade de dominação e poder do campo em questão (BOURDIEU, CHAMBOREDON; PASSERON, 2002). No entanto, ainda que exista a distribuição desigual dos capitais entre os agentes, os mesmos compartilham do mesmo espaço, estando de um lado, os agentes que visam firmar o status de dominantes, e do outro, aqueles que com poucos capitais pensam em estratégias de reprodução para se manterem ativos no campo (BOURDIEU, 1990; 1996b). Esse é o caso dos amadores que fazem a prática do LoL, tendo como influência os especialistas da modalidade.

Atualmente, muitos dos jogadores casuais acompanham o trabalho dos ciber (atletas). E com o crescimento das streams, ficou muito mais fácil assistir em tempo real a performance dos pro players. De fato, face a essa possibilidade, os jogadores amadores podem apreender muito mais observando as partidas entre profissionais, do que apenas jogando com seus pares. Pois, ao ter contato com o estilo e a mecânica de jogo dos especialistas, os amadores podem filtrar informações a serem reproduzidas no subespaço o qual fazem parte. Porém, não se trata somente de uma reprodução do jogo. A reprodução é inventiva, uma vez que os jogadores amadores têm mais liberdade para testar diversos tipos de estratégias, permitindo a hibridização de diversos estilos. Ou seja, embora estejamos nos referindo de agentes com capital ciber (esportivo) menor, os mesmos não estão alheios ao universo que cerca o subcampo dos profissionais.

Em se tratando de capitais, é evidente que os agentes que ocupam a posição dos amadores possuem menos capitais em relação à prática. Nessa esteira, um dos primeiros fatores de distinção, pode estar atrelado ao capital econômico, tendo em vista que no 
Matheus Borsato, Vinicius Machado de Oliveira, Da Produção Especializada à Inventividade Amadora... Marcos Roberto Brasil, Verônica Volski e

Juliano de Souza

subcampo dos especialistas há mais recompensas e troféus em jogo. E como se sabe, o capital econômico pode ser a força motriz para o acúmulo de outros capitais (BOURDIEU, 1996a), muito embora essa condição se justifique apenas dentro do campo do LoL, existindo a consciência de que os amadores podem acumular esse tipo de capital em outras esferas. E na verdade, se refletido mais afundo, o capital econômico dos especialistas pode ser produto da própria participação dos jogadores casuais, que em maior número, alimentam e sustentam o subcampo dos especialistas, dado que consomem muitas das vezes os produtos disponibilizados no universo profissional.

Em linhas gerais, muitos dos agentes que compõem o subcampo dos amadores, acabam utilizando os mesmos produtos que são fornecidos aos profissionais. Um exemplo clássico de e-Sports como o LoL, são os periféricos, utilizados durante a prática, como mouse, teclado, headphone, monitor, etc. De forma geral, trata-se de componentes de alta performance que contribuem para o ganho de precisão e produtividade no jogo. Nesse sentido, como os especialistas influenciam a prática por possuírem o capital simbólico e o status de dominante do campo do LoL, os amadores acabam por consumir dos mesmos produtos, catapultando as marcas que patrocinam o subcampo dos especialistas.

Mas, percebe-se que o capital simbólico que os profissionais detêm é verdadeiramente instável, pois se sustenta, em grande medida, a partir do interesse do círculo dos amadores. Isto é, esse tipo de capital apresenta grandes fragilidades e está constantemente em xeque. Segundo Bourdieu, o capital simbólico é “[...] um capital que se apóia necessariamente nos outros, no olhar e na fala dos outros" (BOURDIEU, 2007, 
Matheus Borsato, Vinicius Machado de Oliveira, Da Produção Especializada à Inventividade Amadora... Marcos Roberto Brasil, Verônica Volski e

Juliano de Souza

p. 389). Portanto, se o interesse dos amadores arrefecer face a dinâmica do subcampo dos especialistas, toda a força estrutural do campo do LoL é colocada em suspense.

Nessa mesma linha de raciocínio, os profissionais podem acumular diversos tipos de capitais (econômico, esportivo, social) que ajudam a consubstanciar um capital simbólico no campo da prática. Mas, como se trata de um espaço que é operacionalizado de acordo com categorias de percepção e princípios de visão, se consideramos a palavra de Bourdieu (1996a), o subcampo dos especialistas opera com pouca autonomia, visto que esse é um dos principais problemas entre aqueles que possuem capital simbólico, segundo Saint Martin (2017). Dessa forma, os amadores que praticam o LoL são tão responsáveis pela sustentação do campo quanto os profissionais.

Todavia, ainda sim, é nítido a interferência do subcampo dos especialistas na esfera dos reprodutores. O reconhecimento aos pro players se tornou tão intenso, que recentemente amadores começaram a comprar aulas virtuais com os profissionais da prática, as chamadas LoLclass. Em consonância com essa estratégia, os profissionais se aproximaram ainda mais do subcampo dos reprodutores, passando a transmitir com regularidade a rotina de treinos e jogatinas ao vivo, que geralmente são acompanhadas por milhares de pessoas. Como exemplo mais recente, podemos citar o caso do jogador profissional Jian Zi-Hao, que durante transmissão de stream, conseguiu ter uma audiência de 8,5 milhões de pessoas assistindo de forma simultânea (SPORTV, 2018).

É nessa aproximação que podemos comprovar o impacto e o poder do subcampo dos especialistas entre os jogadores casuais, sobretudo na transferência de informações e códigos de comportamento que são absorvidos pelos amadores. Nesse quadro, podemos verificar a utilização de gírias pelos profissionais, que ao serem gestadas por esses agentes, se transferem para o ambiente dos reprodutores. Esses últimos, por sua vez, 
Matheus Borsato, Vinicius Machado de Oliveira, Da Produção Especializada à Inventividade Amadora... Marcos Roberto Brasil, Verônica Volski e

Juliano de Souza

reproduzem esse comportamento com os pares do mesmo nível, porém, de forma inventiva, já que podem mobilizar as gírias para diferentes contextos. Inclusive, tais gírias ganham tanta repercussão que, em alguns casos, elas se reproduzem no vestuário, como em camisetas, bottons, etc. (CARDOSO, 2016). E falando de vestuário e de uma prática ciber (esportiva), é claro que os amadores compram os uniformes de suas equipes favoritas, demonstrando suas influências e afinidades com a esfera profissional.

Diante dessa influência dos profissionais sobre os amadores, observa-se pelo motor de análise bourdieusiano, um poder simbólico entre os grupos. Isto é, um poder que não está totalmente explícito e visível aos agentes que dividem o campo (BOURDIEU, 1998). Nessa linha argumentativa, nota-se que os amadores possuem um grau de submissão ao subcampo dos profissionais, quando passam a consumir os inúmeros produtos vinculados à atividade dos especialistas, bem como os códigos de comportamento e o habitus incutido na estrutura profissional do LoL. Como exemplo, podemos mobilizar a própria lógica das streams transmitidas pelos profissionais, que muitas das vezes são realizadas com o intuito de ganhar visibilidade e capitalizar com a audiência, tendo em vista que durante as transmissões, os profissionais monetizam os vídeos, além, é claro, de receberem doações dos amadores que acompanham as streams. Nessa senda, os especialistas não estão ali apenas para interagir com os jogadores de menor nível, existem interesses próprios, que tem muito mais haver com o acúmulo de capitais do que com a relação recíproca entre grupos.

Não obstante, muitos que compõem o subcampo dos amadores não tem essa leitura, justamente por não captarem os elementos de dominação da prática. Portanto, como destaca Bourdieu “o poder simbólico é, com efeito, esse poder invisível o qual só pode ser exercido com a cumplicidade daqueles que não querem saber que lhe estão 
Matheus Borsato, Vinicius Machado de Oliveira, Da Produção Especializada à Inventividade Amadora... Marcos Roberto Brasil, Verônica Volski e

Juliano de Souza

sujeitos ou mesmo que o exercem" (BOURDIEU, 1998. p. 7-8). Em outras palavras, ainda que exista "uma cumplicidade objetiva" entre os grupos, há poderes indiscriminados e velados no campo do LoL, sendo que talvez seus agentes não tenham tal noção. E como já mencionado, talvez nem os próprios amadores tenham a dimensão de quão poderosos são em relação a esse campo, tendo em vista a participação decisiva desses agentes para a expansão do LoL.

Em suma, esses jogadores casuais, em grande medida, são os responsáveis pelo sucesso dessa prática, pois não fazem parte apenas de um espaço de reprodução, mas também, de um subcampo que é inventivo, na medida em que seus agentes possuem reflexividade para atribuir novos contornos e significados a prática. Assim, como são agentes ativos diante do entretenimento (JENKINS, 2008), os amadores movimentam o campo do LoL, ou melhor, apresentam certo ativismo em relação à prática (MACEDO, AMARAL FILHO, 2016), divulgando, discutindo e defendendo esse ciber (esporte) em blogs, sites, fóruns, redes sociais e entre outras plataformas. Enfim, não há como explorar todos os elementos que compõem o amadorismo do LoL, mas de um modo geral, as pistas esquadrinhadas neste estudo, nos ilustram um pouco sobre esse subcampo, que é permeado por uma lógica de reprodução inventiva.

\section{Considerações Finais}

Após a breve digressão sobre o campo do LoL realizada em nossa pesquisa, pudemos identificar importantes aspectos que fundamentam a prática dessa nova atividade do século XXI. Para além da tão somente descrição desse ciber (desporto) ou e-Sport, traçamos como meta, indicar os sinais que o LoL apresenta inúmeras características, que nos fazem entendê-lo como um esporte, assim como qualquer outro. 
Matheus Borsato, Vinicius Machado de Oliveira, Da Produção Especializada à Inventividade Amadora... Marcos Roberto Brasil, Verônica Volski e

Juliano de Souza

Dentre as principais circunstâncias, procuramos demonstrar a estrutura do profissionalismo e amadorismo dessa atividade. Nessa direção, e subsidiados pela leitura sociológica, pudemos constatar que o LoL possui em sua estrutura um espaço competitivo, que é permeado por lutas, distinção, distribuição desigual de capitais, dominantes e dominados, poder simbólico, reprodução, inventividade, entre outras evidências.

Durante a investigação dos subcampos do LoL, observamos que os especialistas da modalidade possuem uma grande influência no círculo dos amadores. Em linhas gerais, aquilo que é semeado e gestado no quadro do profissionalismo, se transfere e se reproduz entre os jogadores casuais. No entanto, a reprodução a qual se testemunha, não se refere a uma simples imitação, mas sim a uma reprodução levada a cabo de maneira reflexiva, que estimula a inventividade. Ou seja, ainda que os amadores apresentem certo grau de submissão ao subcampo profissional, os mesmos ajudam a dinamizar e expandir o campo deste e-Sport. Mais do que isso, ao contribuírem para o aumento da visibilidade dos profissionais, os amadores acabam atribuindo poder simbólico aos especialistas, garantindo assim uma espécie de "cumplicidade objetiva" que sustenta o campo do LoL. Assim, ambos os grupos de agentes são importantes para a manutenção da estrutura da prática, muito embora exista capitais e poderes simbólicos que estão ocultos face à compreensão dos agentes.

Por fim, diante das informações investigadas, podemos chegar a conclusão que o LoL em sua essência, possui um compêndio de fatores que nos permite aceitá-lo como uma prática esportiva do século XXI. Embora tenhamos a consciência da polarização e tensionamentos entre as atividades tradicionais e (pós) modernas, observa-se no LoL, elementos que são caros aos esportes tradicionais. Portanto, não há como simplesmente 
Matheus Borsato, Vinicius Machado de Oliveira, Da Produção Especializada à Inventividade Amadora... Marcos Roberto Brasil, Verônica Volski e

Juliano de Souza

ignorar as hipóteses e evidências aqui escrutinadas. Em suma, estamos a frente de um novo fenômeno do campo das práticas corporais que merece atenção.

\section{REFERÊNCIAS}

ALMEIDA, S. A aprendizagem estratégica e a geração PlayStation: o que está em jogo?. Saber (e) Educar, n. 13, p. 187-197, 2008.

ARAUJO, B. Jogadores profissionais de games têm direito a carteira assinada? Entenda. 2018. Disponível em: http://g1.globo.com/pop-arte/games/noticia/jogadoresprofissionais-de-games-tem-direito-a-carteira-assinada-entenda.ghtml Acesso em: 27 ago. 2018.

BECK, U. Sociedade de risco: rumo a uma outra modernidade. São Paulo: Ed. 34, 2010.

.; GIDDENS, A.; LASH, S. (orgs). Modernização reflexiva: política, tradição, estética na ordem social moderna. São Paulo: Editora da Unesp, 1997.

BELL, C. E. Sexualization and Gamer Avatar Selection in League of Legends. Atlantic Journal of Communication, v. 25, n. 2, p.65-87, mar. 2017.

BERTRAN, E.; CHAMARRO, A. Videogamers of League of Legends: the role of passion in abusive use and in performance. Adicciones, v. 28, n. 1, 2016.

BOURDIEU, P. A dominação masculina. 11. ed. Rio de Janeiro: Bertrand Brasil, 2012.

. As regras da arte: gênese e estrutura do campo literário. São Paulo: Companhia das Letras, 1996b.

Coisas ditas. São Paulo: Brasiliense, 1990.

. O Poder Simbólico. Rio de Janeiro: Bertrand Brasil, 1998.

O senso prático. Tradução de Maria Ferreira. Petrópolis: Vozes, 2009. p. 9-40.

. Postface. La noblesse: capital social et capital symbolique. In: LANCIEN, Didier; SAINT MARTIN, Monique de. (Orgs.). Anciennes et Nouvelles aristocraties de 1880 à nos jours. Paris: Ed. de la MSH, 2007.

. Questões de sociologia. Rio de Janeiro: Marco Zero, 1983.

Razões práticas: sobre a teoria da ação. Campinas: Papirus, 1996a.

Sobre o estado. Companhia das Letras, 2014. 
Matheus Borsato, Vinicius Machado de Oliveira, Da Produção Especializada à Inventividade Amadora... Marcos Roberto Brasil, Verônica Volski e

Juliano de Souza

BOURDIEU, P.; CHAMBOREDON, J. C.; PASSERON, J. C. A profissão de sociólogo: preliminares epistemológicas. Tradução de Guilherme João de Freitas Teixeira. 3. ed. Petrópolis: Vozes, 2002.

CARDOSO, T. A influência dos Streamers na comunidade de League of Legends. 2016. Disponível em: http://medium.com/tend\%C3\%AAncias-digitais/como-streamersinfluenciam-uma-comunidade-cbaa0b41a3ff Acesso em: 01 ago. 2018.

DONALDSON, S. Mechanics and Metagame: exploring binary expertise in League of Legends games and culture, v. 12, n. 5, p.426-444, jun. 2015.

ELIAS, N. Introdução à sociologia. Tradução de Maria Luísa Ribeiro Ferreira. Lisboa: Edições 70, 2008.

O processo civilizador: uma história dos costumes. Tradução de Ruy Jungmann. 2. ed. Rio de Janeiro: Jorge Zahar, 2011.

.; DUNNING, E. A busca da excitação. Tradução de Maria Manuela Almeida e Silva. Lisboa: Difel, 1992.

FERRANTINI, M. Entenda a premiação do CBLoL 2018: R\$ 200 mil em disputa. 2018. Disponível em: http://www.techtudo.com.br/noticias/2018/04/entenda-apremiacao-do-cblol-2018-r-200-mil-em-disputa-esports.ghtml Acesso em: 27 ago. 2018.

FINCO, M. D.; FRAGA, A. B. Corpo joystick: cinema, videogames e estilo de vida ativo. Licere, Belo Horizonte, v. 16, n.3, set. 2013.

FU, C.; LEE, J.; BANSAL, M.; BERG, A. C. Video Highlight Prediction Using Audience Chat Reactions. Proceedings of the 2017 Conference on Empirical Methods in Natural Language Processing. p.1-7, 2017. Association for Computational Linguistics. Disponível em: https://aclweb.org/anthology/D17-1102 Acesso em: 27 ago. 2018.

GIDDENS, A. As consequências da modernidade. São Paulo: Editora Unesp, 1991.

GOETOMO, F. Esports in Korea: a study on League of Legends team performances on the share price of owning corporations. California, 2016, $60 \mathrm{f}$. Senior Theses (Bachelor of arts) - Economics Department, Claremont Mckenna College - CMC, California, 2016.

GRAY, P. B.; VUONG, J.; ZAVA, D. T.; MCHALE, T. S. Testing men's hormone responses to playing League of Legends: No changes in testosterone, cortisol, DHEA or androstenedione but decreases in aldosterone. Computers in Human Behavior, v. 83, p.230-234, jun. 2018.

HONORATO, R. 'League of legends' chega ao Brasil - e em português. 2012. Disponível em: http://veja.abril.com.br/tecnologia/league-of-legends-chega-ao-brasil-eem-portugues/. Acesso em: 21 de jun. 2018. 
Matheus Borsato, Vinicius Machado de Oliveira, Da Produção Especializada à Inventividade Amadora... Marcos Roberto Brasil, Verônica Volski e

Juliano de Souza

JENKINS, H., Cultura da Convergência. São Paulo: Aleph, 2008.

KAHN, A. S. et al. The Trojan Player Typology: A cross-genre, cross-cultural, behaviorally validated scale of video game play motivations. Computers in Human Behavior, v. 49, p.354-361, ago. 2015.

KOKKINAKIS, A. V.; LIN, J.; PAVLAS, D.; WADE, A. R. What's in a name? Ages and names predict the valence of social interactions in a massive online game. Computers in Human Behavior, v. 55, p. 605-613, feb. 2016.

LAHIRE, B. Campo. In: CATANI, A. M. et al. (Orgs.). Vocabulário Bourdieu. Belo Horizonte: Autêntica, 2017.

LEITINHO, R. R.; FARIAS, J. S. A Motivação Hedônica no Consumo de Bens Virtuais Cosméticos em Jogos Online. Revista Brasileira de Marketing, v. 17, n. 01, p.65-79, 1 mar. 2018.

LI, R. Good luck, have fun: The rise of esports. Delaware: Skyhorse, 2016.

LLORENS, M. R. ESport Gaming: The Rise of a New Sports Practice. Sport, Ethics And Philosophy, v. 11, n. 4, p.464-476, 25 abr. 2017.

MACEDO, T.; AMARAL FILHO, O. A anatomia de um movimento comunicativo online: o ativismo de fã-gamers em League of Legends como inteligência coletiva. Revista Geminis, v. 7, n. 1, p. 147-176, 2016.

MORA-CANTALLOPS, M.; SICILIA, M. Á. Player-centric networks in League of Legends. Social Networks, v. 55, p.149-159, out. 2018.

NEWZOO. Brazil Games Market 2018. 2018b. Disponível em: http://newzoo.com/insights/infographics/brazil-games-market-2018/ Acesso em: 30 ago. 2018.

Newzoo's 2018 Report: Insights Into the $\$ 137.9$ Billion Global Games Market. 2018a. Disponível em: http://newzoo.com/insights/articles/newzoos-2018report-insights-into-the-137-9-billion-global-games-market/ Acesso em: 30 ago. 2018.

PALFREY, J.; GASSER, U. Nascido na era digital: entendendo a primeira geração de nativos digitais. Porto Alegre: Artmed, 2011.

PETRÓ, G. 'League of legends' ganha servidor localizado no brasil. 2013. Disponível em: https://g1.globo.com/tecnologia/noticia/2013/02/league-legends-ganhaservidor-localizado-no-brasil.html. Acesso em: 21 jun. 2018.

PRENSKY, M. Digital Natives, Digital Immigrants Part 1. On The Horizon, v. 9, n. 5, p. 1-6, sep. 2001.

RIBEIRO, N. League o Legends: conheça as principais ligas de LoL do mundo. 2018. Disponível em: http://www.techtudo.com.br/noticias/2018/08/league-of-legendsconheca-as-principais-ligas-de-lol-do-mundo-esports.ghtml Acesso em: 27 ago. 2018. 
Matheus Borsato, Vinicius Machado de Oliveira, Da Produção Especializada à Inventividade Amadora... Marcos Roberto Brasil, Verônica Volski e

Juliano de Souza

RIPAMONTI, L. A. et al. Multi-agent simulations for the evaluation of Looting Systems design in MMOG and MOBA games. Simulation Modelling Practice and Theory, v. 83, p.124-148, abr. 2018.

ROCHA, M.; RODRIGUEZ, V. B.; VITÓRIA, F. F. T. Impacto do patrocínio de esport na decisão de compras dos jogadores de League of Legends da Bahia. Seminário Estudantil de Produção Acadêmica, v. 15, 2016.

RODRIGUES, B. Mundial de LoL teve mais de 80 milhões de espectadores em série única. 2017. Disponível em: http://www.maisesports.com.br/audiencia-mundial-2017lol/ Acesso em: 27 ago. 2018.

ROX, M. 8 times brasileiros de futebol que já apareceram nos eSports. 2017. Disponível em: http://www.theenemy.com.br/league-legends/league-of-legends/8times-brasileiros-de-futebol-que-ja-apareceram-nos-esports Acesso em: 27 ago. 2018.

SAINT MARTIN, M. Capital simbólico. In: CATANI, Afrânio Mendes et al. (Orgs.). Vocabulário Bourdieu. Belo Horizonte: Autêntica, 2017.

SAPIENZA, A.; BESSI, A.; FERRARA, E. Non-Negative Tensor factorization for human behavioral pattern mining in online games. Information, v. 9, n. 3, mar. 2018.

SAPIENZA, A.; ZENG, Y.; BESSI, A.; LERMAN, K.; FERRARA, E. Individual performance in team-based online games. Royal Society Open Science, v. 5, n. 6, p.114, jun. 2018.

SOUZA, J.; MARCHI JÚNIOR, W. O "match do século" e a "história esportiva" do xadrez - uma interpretação sociológica. Motriz, Rio Claro, v.19 n.2, p.399-411, abr./jun. 2013.

SPORTV. Cleveland Cavaliers, Golden State Warriors e Houston Rockets disputarão liga de LoL. 2017. Disponível em: http://sportv.globo.com/site/esportv/noticia/cleveland-cavaliers-golden-state-warriors-e-houston-rockets-disputaraoliga-de-lol.ghtml Acesso em: 03 set. 2018.

SPORTV. Jogador de LoL bate 8,5 milhões de espectadores simultâneos em stream. 2018. Disponível em: http://sportv.globo.com/site/e-sportv/noticia/jogador-delol-bate-85-milhoes-de-espectadores-simultaneos-em-stream.ghtml Acesso em: 31 ago. 2018.

ŠTAVLJANIN, V.; CVIJOVIĆ, J.; KOSTIĆ-STANKOVIĆ, M. Research of indirect advertising in video game industry. Industrija, v. 45, n.4, p. 113-132, 2017.

TAPSCOTT, D. Growing Up Digital: The Rise of the Net Generation. New York: Mcgraw-Hill, 1997.

WATSON, M. A medley of meanings: Insights from an instance of gameplay in League of Legends. Journal of Comparative Research in Anthropology and Sociology, v. 6, n.1, p. 225-243, 2015. 
Matheus Borsato, Vinicius Machado de Oliveira， Da Produção Especializada à Inventividade Amadora... Marcos Roberto Brasil, Verônica Volski e

Juliano de Souza

\section{Endereço dos Autores:}

Matheus Borsato

Rua dos Pombos, 170 - Bonsucesso

Guarapuava - PR - 85.035-440

Endereço Eletrônico: mthsbrst@gmail.com

Vinicius Machado de Oliveira

Rua dos Abacateiros, 70 - Conradinho

Guarapuava - PR - 85.060-450

Endereço Eletrônico: oliveira_vm@hotmail.com

Marcos Roberto Brasil

Rua Antonio Gregório Ferreira, 153 - Conradinho

Guarapuava-PR - 85.055-270

Endereço Eletrônico: brasillmr@hotmail.com.br

Verônica Volski

Rua Andrade Neves, 2016, apto 201 - Santa Cruz

Guarapuava - PR - 85.015-210

Endereço Eletrônico: vero_edf@hotmail.com

Juliano de Souza

Universidade Estadual de Maringá

Secretaria do Programa de Pós-Graduação em Educação Física

Av. Colombo, 5790 - Campus Universitário

Maringá - PR - 87.020-900

Endereço Eletrônico: julianoedf@hotmail.com 